\title{
Cronstedtite polytypes in the Paris meteorite
}

\author{
Isabella Pignatelli ${ }^{1, *}$, Enrico Mugnaioli ${ }^{2,3}$, Yves Marrocchi $^{1}$ \\ ${ }^{1}$ CRPG, UMR 7358, CNRS - Université de Lorraine, 54500 Vandoeuvre-lès-Nancy, France \\ ${ }^{2}$ Dipartimento di Scienze Fisiche, della Terre e dell'Ambiente, Università degli Studi di Siena, Via \\ Laterino 8, 53100 Siena, Italy \\ ${ }^{3}$ Center for Nanotechnology Innovation@ NEST, Istituto Italiano di Tecnologia, Piazza San Silvestro \\ 12, 56127, Pisa, Italy \\ *e-mail address of the corresponding author: isabella.pignatelli@univ-lorraine.fr
}

\begin{abstract}
The first detailed crystallo-chemical and crystallographic description of cronstedtite with extraterrestrial origin has been presented in this study. The analysed crystals have been found in the Paris meteorite, which is the least altered carbonaceous chondrite currently known, and they result from the pseudomorphism of anhydrous silicates. 3D electron diffraction collected by combining electron diffraction tomography (EDT) and precession electron diffraction (PED) are used to identify the cronstedtite polytypes, because of their small size. All identified polytypes are MDO, and the most abundant one is $1 T$. Many other crystals also belong to the subfamily $\mathrm{C}$, but their stacking disorder hampers the polytype identification. Only in a crystal, the $3 T$ and $2 M_{1}$ polytypes are recognised. TEM-
\end{abstract}


EDX data indicate that the chemical composition of the crystals is similar, regardless their polytypic sequence.

Key-words: cronstedtite, MDO polytypes, 3D electron diffraction, Paris meteorite.

\section{Introduction}

Cronstedtite is an iron-rich phyllosilicate whose layer is made of a tetrahedral (T) and an octahedral (O) sheet (T-O or 1:1 layer). The octahedral sheet is trioctahedral (Bailey, 1969) meaning that all cation sites are occupied almost exclusively by iron (both $\mathrm{Fe}^{2+}$ and $\mathrm{Fe}^{3+}$ ), even if small amount of other cations such as $\mathrm{Mg}^{2+}, \mathrm{Mn}^{2+}$ and $\mathrm{Al}^{3+}$ have been reported (Frondel, 1962; Geiger et al., 1983; Hybler et al., 2002). $\mathrm{Fe}^{3+}$ is also present in the tetrahedral sheet and this allows for discriminating cronstedtite from other Fe-bearing phyllosilicates, in particular greenalite. According to that, the general formula of cronstedtite is $\left(\mathrm{Fe}^{2+}{ }_{3-x} \mathrm{Fe}^{3+}{ }_{x}\right)\left(\mathrm{Si}_{2-x} \mathrm{Fe}^{3+}{ }_{x}\right) \mathrm{O}_{5}(\mathrm{OH})_{4}$ with $0<x<0.8$ (Geiger et al., 1983; Smrčok et al., 1994; Hybler et al., 2000, 2002; Kogure et al., 2002).

From the structural point of view, the absence of interlayer cations makes the polytypism of cronstedtite, as well as of other T-O phyllosilicates, more complex than in micas because the adjacent layers can be stacked with a shift and/or rotation (Bailey, 1969). Twelve maximum degree of order (MDO) polytypes have been theoretically derived by Bailey (1969) and classified in four groups also called subfamilies in the Order-Disorder theory (Dornberger-Schiff \& Durovič 1975): group A (1M, $\left.2 M_{1}, 3 T\right)$ which is characterized by $\pm a_{\mathrm{i}} / 3$ shifts between adjacent layers; group $\mathrm{B}\left(2 O, 2 M_{2}, 6 H\right)$ by $\pm a_{\mathrm{i}} / 3$ shifts combined with $180^{\circ}$ rotation; group $\mathrm{C}(1 T, 2 T, 3 R)$ by $\pm b / 3$ or no shifts; and group $\mathrm{D}$ $\left(2 H_{1}, 2 H_{2}, 6 R\right)$ by $\pm b / 3$ or no shifts combined with $180^{\circ}$ rotation, where $a_{\mathrm{i}}$ and $b$ correspond to the hexagonal and orthohexagonal unit-cell vectors respectively. In literature, only eight of MDO polytypes have been reported for cronstedtite $\left(1 T, 1 M, 2 H_{1}, 2 H_{2}, 2 M_{1}, 2 T, 3 T, 6 R\right)$ but none of them 
belongs to the group B (Steadman \& Nuttall., 1963, 1963; Kogure et al., 2001). Two non-MDO polytypes of cronstedtite are also known: $9 R$ polytype found at Cournocopia Mines (Nevada, USA) (Frodel, 1962), and 6 $T_{2}$ polytype recently identified in Pohled (Czech Republic) samples (Hybler et al., 2016; Hybler, 2016).

Cronstedtite can exhibit intergrowths of two polytypes of the same group, for example $3 T+1 M$, $2 H_{1}+2 H_{2}$, and the possible intergrowth of $2 M_{1}$ and $6 T_{2}$ (Durovič, 1997; Kogure et al., 2001; Hybler et al., 2016, 2017), as well as the intergrowths of polytypes of groups A and C (Kogure et al., 2001, 2002). Recently, the existence of twinning in cronstedtite has been also proved: twins by reticular merohedry of the $3 T$ and $6 T_{2}$ polytypes have been described in samples from Nižná Slaná and Pohled, (Hybler et al., 2016, 2017).

Cronstedtite occurs in both terrestrial and extraterrestrial environments. On the Earth, cronstedtite is found in: i) low-temperature hydrothermal veins of sulfides (Frondel, 1962); ii) metamorphosed massive sulphide deposits (López-García et al., 1992); iii) hydrothermal quartz veins intersecting metasomatic siderite deposits (Hybler et al., 2017); iv) hydrothermal veins containing pyrite developed in migmatized rocks (Hybler et al., 2016). An iron-rich phyllosilicate identified as possibly cronstedtite is formed with low-temperature retrograde minerals of banded-iron formations in Australian metabasites (Gole, 1980a,b).

Spectroscopic data let suppose that cronstedtite formed also in extraterrestrial environments, such as in some dark regions of Mars (Calvin, 1998) and on the dwarf planet Ceres (Zolotov, 2014 and references therein). Moreover, cronstedtite is reported in CM meteorites (e.g. Tomeoka \& Buseck, 1985; McSween et al., 1979; Pignatelli et al., 2016), although its identification is questionable. In fact, what is described as "cronstedtite" in meteoritic studies is often a solid solution of T-O phyllosilicates, e.g. chysotile and greenalite or chrysotile and cronstedtite (Velbel, 2014), leading to confusion and misunderstanding. Few data are known about the polytypism of meteoritic cronstedtite: $1 T$ polytype is 
found in Cold Bokkeveld and Cochamba meteorites, but the latter also contains the $1 M$ polytype and an unidentified polytype with the cell parameter $c \approx 14 \AA$ (Zega \& Buseck, 2003; Müller et al., 1979).

Thus, the aim of this work is to improve the current knowledge about the polytypism of meteoritic cronstedtite, describing the polytypes recently found in Paris meteorite and identified by 3D electron diffraction data.

\section{Material and methods}

Paris meteorite is the least altered carbonaceous chondrite belonging to the CM group (Hewins et al., 2014). It is characterized by $47 \%$ of matrix, $45 \%$ of chondrules and $8 \%$ of fine-grained rims; and it contains both fresh and more altered domains (Hewins et al., 2014; Leroux et al., 2015; VerdierPaoletti et al., 2016; Vacher et al., 2017). Pseudomorphised silicates are dispersed throughout the matrix regardless of the alteration degree of domains. They are characterized by a complex compositional zoning made of three different Fe-bearing secondary minerals: tochilinite, cronstedtite and hydroxides (Pignatelli et al., 2016, 2017).

Cronstedtite crystals found in pseudomorphised olivine and pyroxene of Paris meteorite were analysed in this study. For this purpose, two thin foils were extracted from the \#2010-1section of Paris with a FEI strata DualBeam 235 at the Institute d' Electronique, de Microélectronique et de Nanotechnologie (Lille, France), using a lift-out procedure described by Heaney et al. (2001). The FIB foils were analysed at Università degli Studi di Siena (Italy) with a JEOL 2010 microscope operated at $200 \mathrm{kV}$ and equipped with $\mathrm{LaB}_{6}$ gun and UHR pole pieces able to achieve a point-to-point resolution of 0.19 nm. The chemical composition of cronstedtite crystals was determined by energy dispersive X-ray (EDX) spectroscopy using an Oxford ISIS spectrometer with a probe diameter of $\sim 100 \mathrm{~nm}$, a counting time of $60 \mathrm{~s}$, a dead time lower than $15 \%$, and $\mathrm{K}_{\mathrm{AB}}$ factors calibrated on standards. The structural formulae were calculated on the basis of seven oxygens and of the $\mathrm{Fe}^{3+} / \Sigma \mathrm{Fe}$ ratio measured by $\mathrm{X}$-ray 
adsorption near-edge structure spectroscopy (XANES). The details on $\mathrm{Fe}^{3+} / \Sigma \mathrm{Fe}$ measurements and results are given in Pignatelli et al. (2017).

3D electron diffraction data were collected by combining electron diffraction tomography (EDT) (Kolb et al., 2007; Kolb et al., 2008; Mugnaioli, 2015) and precession electron diffraction (PED) (Vincent \& Midgley, 1994; Mugnaioli et al., 2009) at the Università degli Studi di Siena (Italy). Sequential selected area electron diffraction (SAED) patterns were collected with an Olympus Tengra CCD camera in a tilt range of up to $-40 /+40^{\circ}$ with a step of $1^{\circ}$, using an area selector of $10 \mu \mathrm{m}$, equivalent to a beam size on the sample of about $100 \mathrm{~nm}$. ADT3D software and in-house Matlab routines were used for the data processing, including three-dimensional reciprocal space reconstruction, cell parameter determination and intensity integration. The advantages of electron diffraction tomography for characterizing nanometric crystals, such as those in meteorites, are detailed in Kolb et al. (2011) and Pignatelli et al. (2014).

\subsection{Features of diffraction pattern of T-O phyllosilicates}

On the basis of Order-Disorder theory, it is possible to distinguish two kinds of reflections in the diffraction patterns of T-O phyllosilicates: family, and non-family reflections. The family reflections $00 l$ are common to all polytypes of the same family (i.e. T-O phyllosilicates in this case). Family reflections having $k=3 n$ (in orthohexagonal indexing, or $h-k=3 n$ in hexagonal indexing) are common to all polytypes belonging to the same subfamily, thus they are generally referred as "subfamily reflections". They enable for identification of subfamilies or Bailey's groups A, B, C and D in function of the shift and/or rotation between adjacent layers. The non-family reflections with $k=3 n$ (in orthohexagonal indexing, or $h-k=3 n$ in hexagonal indexing) are typical of each polytype and are, thus, used to identify the stacking sequence. These reflections are affected by diffuse streaking and appear broadened when the polytype is disordered. 
Diffraction patterns of two orthogonal reciprocal lattice sections are usually sufficient to identify an MDO polytype: the diffraction pattern of $(h 0 l)^{*}(h h l$ in hexagonal indexing) containing the subfamily reflections and the diffraction pattern of $(0 \mathrm{kl})^{*}(\bar{h} h l$ in hexagonal indexing), containing both subfamily and non-family reflections (Ďurovič, 1997). However, the diffraction pattern of the $(0 k l)^{*}$ plane is different from that of $(h 0 l)^{*}$ in non-trigonal and non-hexagonal poytypes, because they are not symmetrically equivalent (Hybler, 2014). This means that for the identification of such polytypes both planes have to be recorded and analyzed.

\section{Results and discussion}

\subsection{Crystallo-chemistry}

TEM-EDX data indicate that cronstedtite crystals have low amounts of $\mathrm{Mg}$ and $\mathrm{Al}$, i.e. $\leq 8.09$ and 2.25 at. $\%$ (Table 1 and 2), substituting iron in both octahedral and tetrahedral sites. The averaged $\mathrm{Fe}^{3+} / \Sigma \mathrm{Fe}$ ratio for cronstedtite crystals formed from a pyroxene and olivine precursors is respectively of $36.5 \%$ and $48 \%$ (Pignatelli et al., 2017). According to these data, the mean formulae are:

$$
\begin{aligned}
& \left(\mathrm{Fe}^{2+}{ }_{1.56} \mathrm{Fe}^{3+}{ }_{0.87} \mathrm{Mg}_{0.50}\right)_{\Sigma=2.93}\left(\mathrm{Si}_{1.27} \mathrm{Fe}^{3+}{ }_{0.57} \mathrm{Al}_{0.15}\right)_{\Sigma=1.99} \mathrm{O}_{5}(\mathrm{OH})_{4} \quad \text { [olivine precursor] } \\
& \left(\mathrm{Fe}^{2+}{ }_{2.01} \mathrm{Fe}^{3+}{ }_{0.61} \mathrm{Mg}_{0.43}\right)_{\Sigma=3.04}\left(\mathrm{Si}_{1.31} \mathrm{Fe}^{3+}{ }_{0.55} \mathrm{Al}_{0.14}\right)_{\Sigma=2.00} \mathrm{O}_{5}(\mathrm{OH})_{4} \quad \text { [pyroxene precursor] }
\end{aligned}
$$

The formulae indicate that: (i) cronstedtite in Paris meteorite shows a composition similar to those reported for terrestrial one (e.g., Smrčok et al., 1994; Hybler et al., 2000); and (ii) there is no significant compositional variation among cronstedtite crystals with different precursors, i.e. olivine and pyroxene, suggesting that they formed under the same conditions. 


\subsection{Polytypes found}

In order to identify the polytypes, we compared the distribution of reflections on electron diffraction 2D patterns with the identification diagrams for MDO cronstedtite polytypes available in literature (Durovič, 1997; Hybler et al., 2008) and with the diffraction patterns calculated theoretically by using the DIFK91 program (Smrčok and Weiss, 1993).

The results underline that the most common polytype occurring in the analyzed FIB foils is $1 T$ (Fig.1). This polytype belongs to the subfamily $\mathrm{C}$ as shown by the reflections' distribution along the $[11 l]^{*}$ row on the $\left(h h l_{\text {hex }}\right)^{*}$ plane (Fig. 2a). Moreover, the reflections' distribution on $\left(0 k l_{\text {hex }}\right)^{*}$ plane corresponds to MDO group I (Ďrovič, 1997) and indicates that this is 1-layer polytype (Fig. 2b).

$1 T$ is the most abundant polytype both in terrestrial samples (Hybler et al., 2008) and in few analyzed extraterrestrial ones (Zega \& Buseck, 2003; Müller et al., 1979). The first structural refinement of this polytype was carried out less than two decades ago by Hybler and co-workers (Hybler et al., 2000).

Many cronstedtite crystals are characterized by stacking disorder, resulting in streaking along $c^{*}$ direction. However, a number of these disordered crystals preserve sharp maxima in the $\left(h h l_{\text {hex }}\right)^{*}$ plane, allowing to attribute them to the subfamily C. Also in these cases, streaks still affect the non-family reflections as visible on $\left(0 k l_{\text {hex }}\right)^{*}$ plane of Fig. 3, hampering the polytype identification.

Only one cronstedtite crystal, found close to the remnant of a pseudomorphised olivine (Fig. 4), must necessarily be attributed to a different polytype subfamily. Although reflections are severely streaked, due to a high degree of disorder of this polytype, one can see that: (i) the distribution of reflections along $[11 l]^{*}$ row is consistent with that of polytypes belonging to the subfamily $\mathrm{A}$, and (ii) there are three reflections in the $1 / 7 \AA^{-1}$ period along $[10 l]^{*}$ row, indicating that it is a 3-layer polytype. It is, thus, a $3 T$ polytype. However, the presence of other reflections not attributable to $3 T$ implies its coexistence with other polytypes, probably ordered at the scale of few atomic layers. Reflections belonging to three $1 M$ polytype cannot be excluded, as these would overlap with those of $3 T$. 
Moreover, in some $[10 l]^{*}$ rows the maxima corresponding to $2 M_{1}$ polytype can be recognized. This would be the first time that the contemporary occurrence of $3 T+2 \mathrm{M}_{1}$ polytypes is recognized, as the $3 T$ polytype is commonly described in association with $1 M$ (Ďurovič, 1997; Hybler et al., 2016, 2017).

\section{Conclusions}

This work is the first reliable characterization of cronstedtite in meteorite. Firstly, the crystallochemical and redox data clearly indicate that the analyzed phyllosilicates are cronstedtite sensu stricto whereas in meteoritic studies the word "cronstedtite" is generally used to describe a solid-solution between T-O phyllosilicates with different compositions. Secondly, the polytypic sequences of this mineral were reported in literature only twice due to the small size of the crystals leading to analytical problems. Our results show that the electron diffraction tomography (EDT) combined to the precession electron diffraction (PED) is well adapted to investigate sub-micrometric crystal even those that are beam sensitive. The acquired 3D electron diffraction data allowed for the identification of disordered

polytypes, $1 T$ polytypes as well as a possible coexistence between $3 T$ and $2 M_{1}$. All polytypes have similar chemical composition, regardless of their polytypic sequence. The results presented here can be useful to better reconstruct the formation conditions of cronstedtite in meteorite, taking into account the stability field of different polytypes.

\section{Acknowledgements}

This work was supported by l'Agence Nationale de la Recherche through grant ANR-14-CE33-000201 SAPINS and by the Italian national project FIR2013-Exploring the Nanoworld. 


\section{References}

Bailey, S.W. (1969): Polytypism of trioctahedral 1:1 layer silicates. Clays and Clay Miner., 17, 355371.

Calvin W.M. (1998) Could Mars be dark and altered? Geophys. Res. Lett., 25, 1597-1600.

Dornberger-Schiff, K. \& Ďurovič, S. (1975): OD-interpretation of kaolinite-type structure - I: symmetry of kaolinite packets and their stacking possibilities. Clays and Clay Miner., 23, 219229.

Durovič, S. (1997): Cronstedtite-1M and co-existence of $1 M$ and $3 T$ polytypes. Ceramics - Silikáty, 41, 98-104.

Frondel, C. (1962): Polytypism in cronstedtite. Am. Mineral., 47, 781-783.

Geiger, C.A., Henry, D.L., Bailey, S.W., Maj, J.J. (1983): Crystal structure of cronstedtite-2H. Clays and Clay Miner., 31, 97-108.

Gole, M.J. (1980a): Low-temperature retrograde minerals in metamorphosed Archean banded ironformations, Western Australia. Can. Mineral., 18, 205-214.

Gole, M.J. (1980b): Mineralogy and petrology of very-low metamorphic grade Archean banded ironformations, Weld Range, Western Australia. Am. Mineral., 65, 8-25. 
Heaney, P.J., Vicenzi, E.P., Giannuzzi, L.A., Livi, J.T. (2001): Focused ion beam milling: a method of site-specific sample extraction for microanalysis of earth and planetary materials. Am. Miner., 86, 1094-1099.

Hewins, R.H., Bourot-Denise, M., Zanda, B., Leroux, H., Barrat, J.-A., Humayun, M., Göpel, C., Greenwood, R.C., Franchi, I.A., Pont, S., Lorand, J.-P., Cournède, C., Gattacceca, J., Rochette, P., Kuga, M., Marrocchi, Y., Marty, B. (2014): The Paris meteorite, the least altered CM chondrite so far. Geochim. Cosmochim. Acta, 124, 190-222.

Hybler, J. Sejkora, J., Venclík,V. (2016): Polytypism of cronstedtite from Pohled, Czech Republic. Eur. J. Mineral., 28, 765-775.

Hybler, J. (2014): Refinement of cronstedtite-1M. Acta Crystallogr., B70, 963-972.

Hybler, J. (2016): Crystal structure of cronstedtite-6 $T_{2}$, a non-MDO polytype, Eur. J. Mineral., 26, $777-788$.

Hybler, J., Ďurovič, S., Kogure, T. (2008): Polytypism in cronstedtite. Acta Crystallogr., A64, 498499.

Hybler, J., Petřiček, V., Ďurovič, S., Smrčok, L. (2000): Refinement of the crystal structure of cronstedtite-1T. Clays and Clay Miner., 48, 331-338. 
Hybler, J., Petřiček, V., Ďurovič, S., Smrčok, L. (2000): Refinement of the crystal structure of cronstedtite-1T. Clays and Clay Miner., 48, 331-338.

Hybler, J., Petřiček, V., Fábry, J., Ďurovič, S. (2002): Refinement of the crystal structure of cronstedtite- $2 \mathrm{H}_{2}$. Clays and Clay Miner., 50, 601-613.

Hybler, J., Števko, M., Sejkora, J. (2017): Polytypism of cronstedtite from Nižná Slaná, Slovakia, Eur. J. Mineral., 29, 91-99.

Kogure, T., Hybler, J., Ďrovič, S. (2001): A HRTEM study of cronstedtite: determination of polytypes and layer polarity in trioctahedral 1:1 phyllosilicates. Clays and Clay Miner., 49, 310-317.

Kogure, T., Hybler, J., Yoshida, H. (2002): Coexistence of two polytypic groups in cronstedtite from Lostwithiel England. Clays and Clay Miner., 50, 504-513.

Kolb, U., Mugnaioli, E., Gorelik, T.E. (2011): Automated electron diffraction tomography - a new tool for nano crystal structure analysis. Cryst. Res. Technol., 46, 542-554.

Leroux H., Cuvillier P., Zanda B., Hewins R.H. (2015): GEMS-like material in the matrix of the Paris meteorite and the early stages of alteration of CM chondrites. Geochim. Cosmochim. Acta, 170, $247-265$. 
López García, J.A., Manteca, J.I., Prieto, A.C., Calvo, B. (1992): Primera aparición en España de cronstedtita. Caracterización estructural. Boletín de la Sociedad Española de Mineralogía, 15-1, $21-25$.

McSween, H.Y. (1979): Alteration in CM carbonaceous chondrites inferred from modal and chemical variations in matrix. Geochim. Cosmochim. Acta, 43, 1761-1770.

Müller, W.F., Kurat, G., Kracher, A. (1979): Chemical and crystallographic study of cronstedtite in the matrix of the Cochabamba (CM2) carbonaceous chondrite. Tschermaks Mineral. Petrogr. Mitteilungen, 26, 293-304.

Pettersen, E.F., Goddard, T.D., Huang, C.C., Couch, G.S., Greenblatt, D.M., Meng, E.C., Ferrin, T.E. (2004): UCSF Chimera - a visualization system for exploratory research and analysis. J. Comput. Chem., 25, 1605-1612.

Pignatelli, I., Marrocchi, Y., Mugnaioli, E., Bourdelle, F., Gounelle, M. (2017): Mineralogical, crystallographic and redox features of the earliest stages of fluid alteration in CM chondrites. Geochim. Cosmochim. Acta, 209, 106-122.

Pignatelli, I., Marrocchi, Y., Vacher, L.G., Delon, R., Gounelle, M. (2016): Multiple precursors of secondary mineralogical assemblages in CM chondrites. Meteorit. Planet. Sci., 51, 785-805. 
Pignatelli, I., Mugnaioli, E., Mosser-Ruck, R., Barres, O., Kolb, U., Michau, N. (2014): A multitechnique, micrometer- to atomic-scale description of a synthetic analogue of chukanovite, $\mathrm{Fe}_{2}\left(\mathrm{CO}_{3}\right)(\mathrm{OH})_{2}$. Eur. J. Mineral., 26, 221-229.

Smrcčok, L. \& Weiss, Z. (1993): DIFK91: a program for the modelling of powder diffraction patterns on a PC. J. Appl. Crystallogr., 26, 140-141.

Smrčok, L., Ďurovič, S., Petřiček, V., Weiss, Z. (1994): Refinement of the crystal structure of cronstedtite-3T. Clays and Clay Miner., 42, 544-551.

Tomeoka, K. \& Buseck, P.R. (1985): Indicators of aqueous alteration in CM carbonaceous chondrites: microtextures of a layered mineral containing Fe, S, O and Ni. Geochim. Cosmochim. Acta, 49, 2149-2163.

Vacher, L.G., Marrocchi, Y., Villeneuve, J., Verdier-Paoletti, M., Gounelle, M. (2017): Petrographic and $\mathrm{C} \& \mathrm{O}$ isotopic characteristics of the earliest stages of aqueous alteration of CM chondrites. Geochim. Cosmochim. Acta, 213, 271-290.

Velbel, M.A. (2014): Stoichiometric reactions describing serpentinization of anhydrous primary silicates: a critical appraisal, with application to aqueous alteration of chondrule silicates in $\mathrm{CM}$ carbonaceous chondrites. Clays Clay Miner., 62, 126-136.

Verdier-Paoletti, M., Marrocchi, Y., Avice, G., Gounelle, M. (2016): Oxygen isotope constraints on the alteration temperatures of CM chondrites. Earth Planet. Sci. Lett., 458, 273-281. 
Zega, T.J. \& Buseck, P.R. (2003): Fine-grained-rim mineralogy of the Cold Bokkeveld CM chondrite. Geochim. Cosmochim. Acta, 67, 1711-1721.

Zolotov, M.Y. (2014): Formation of brucite and cronstedtite bearing mineral assemblages on Ceres. Icarus, 228, 13-26. 


\section{Tables}

\begin{tabular}{|c|c|c|c|c|c|c|}
\hline & $\mathrm{O}$ & $\mathrm{Mg}$ & $\mathrm{Al}$ & $\mathrm{Si}$ & $\mathrm{Fe}$ & Total \\
\hline & 62.75 & 8.09 & 0.42 & 7.37 & 21.38 & 100.01 \\
\hline & 62.95 & 4.29 & 0.75 & 7.85 & 24.15 & 99.99 \\
\hline & 63.92 & 4.19 & 2.25 & 10.08 & 19.56 & 100.00 \\
\hline & 65.50 & 2.02 & 0.49 & 8.99 & 23.00 & 100.00 \\
\hline & 65.92 & 3.90 & 0.89 & 8.52 & 20.75 & 99.98 \\
\hline & 66.36 & 3.57 & 1.24 & 8.46 & 20.37 & 100.00 \\
\hline & 66.07 & 4.41 & 1.30 & 9.36 & 18.86 & 100.00 \\
\hline & 64.39 & 4.43 & 2.04 & 10.28 & 18.86 & 100.00 \\
\hline & 65.22 & 2.43 & 0.95 & 9.53 & 21.87 & 100.00 \\
\hline & 66.15 & 1.67 & 0.75 & 8.90 & 22.53 & 100.00 \\
\hline & 67.40 & 2.98 & 1.08 & 7.95 & 20.59 & 100.00 \\
\hline & 68.67 & 2.64 & 0.96 & 8.89 & 18.84 & 100.00 \\
\hline & 66.78 & 2.99 & 0.81 & 9.49 & 19.93 & 100.00 \\
\hline & 66.68 & 3.01 & 0.96 & 9.43 & 19.92 & 100.00 \\
\hline & 64.47 & 3.50 & 1.21 & 10.59 & 20.23 & 100.00 \\
\hline & 64.24 & 3.00 & 1.08 & 7.91 & 23.77 & 100.00 \\
\hline & 68.78 & 2.48 & 0.97 & 7.16 & 20.61 & 100.00 \\
\hline average & 65.66 & 3.51 & 1.07 & 8.87 & 20.90 & \\
\hline$\sigma$ & 1.75 & 1.45 & 0.47 & 1.00 & 1.66 & \\
\hline
\end{tabular}

Table 1. TEM-EDX data of cronstedtite crystals (at \%) formed from an olivine precursor. 


\begin{tabular}{|c|c|c|c|c|c|c|}
\hline & $\mathrm{O}$ & $\mathrm{Mg}$ & $\mathrm{Al}$ & $\mathrm{Si}$ & $\mathrm{Fe}$ & Total \\
\hline & 62.91 & 1.48 & 0.75 & 8.90 & 25.96 & 100.00 \\
\hline & 63.74 & 2.71 & 0.64 & 8.59 & 24.32 & 100.00 \\
\hline & 65.57 & 3.62 & 0.72 & 9.41 & 20.69 & 100.01 \\
\hline & 66.53 & 3.73 & 0.81 & 9.39 & 19.54 & 100.00 \\
\hline & 65.27 & 4.61 & 1.35 & 9.41 & 19.36 & 100.00 \\
\hline & 66.55 & 2.97 & 0.96 & 8.59 & 20.94 & 100.01 \\
\hline & 65.25 & 2.66 & 0.84 & 8.73 & 22.50 & 99.98 \\
\hline & 66.36 & 2.05 & 0.76 & 8.60 & 22.23 & 100.00 \\
\hline & 66.19 & 2.00 & 0.84 & 8.26 & 22.71 & 100.00 \\
\hline & 64.27 & 2.93 & 1.12 & 9.27 & 22.41 & 100.00 \\
\hline & 64.88 & 2.69 & 1.13 & 9.19 & 22.11 & 100.00 \\
\hline & 65.05 & 2.25 & 1.07 & 8.94 & 22.69 & 100.00 \\
\hline & 64.53 & 1.51 & 1.00 & 9.14 & 24.23 & 100.00 \\
\hline & 66.52 & 1.27 & 0.99 & 8.56 & 22.66 & 100.00 \\
\hline & 65.12 & 2.32 & 1.25 & 9.04 & 22.27 & 100.00 \\
\hline & 64.52 & 7.88 & 1.65 & 9.88 & 16.05 & 99.98 \\
\hline & 67.35 & 5.05 & 0.83 & 9.49 & 17.27 & 99.98 \\
\hline & 62.25 & 3.04 & 0.92 & 7.30 & 26.50 & 99.99 \\
\hline & 68.03 & 2.39 & 0.73 & 10.04 & 18.81 & 100.01 \\
\hline & 69.65 & 1.27 & 0.96 & 9.61 & 18.21 & 99.70 \\
\hline & 63.75 & 0 & 0.76 & 9.28 & 26.21 & 100.00 \\
\hline & 68.23 & 4.34 & 1.33 & 9.38 & 16.72 & 100.00 \\
\hline average & 65.55 & 3.00 & 0.98 & 9.23 & 22.21 & \\
\hline$\sigma$ & 1.78 & 1.74 & 0.25 & 1.05 & 4.21 & \\
\hline
\end{tabular}


Table 2. TEM-EDX data of cronstedtite crystals (at \%) formed from a pyroxene precursor.

\section{Figures}

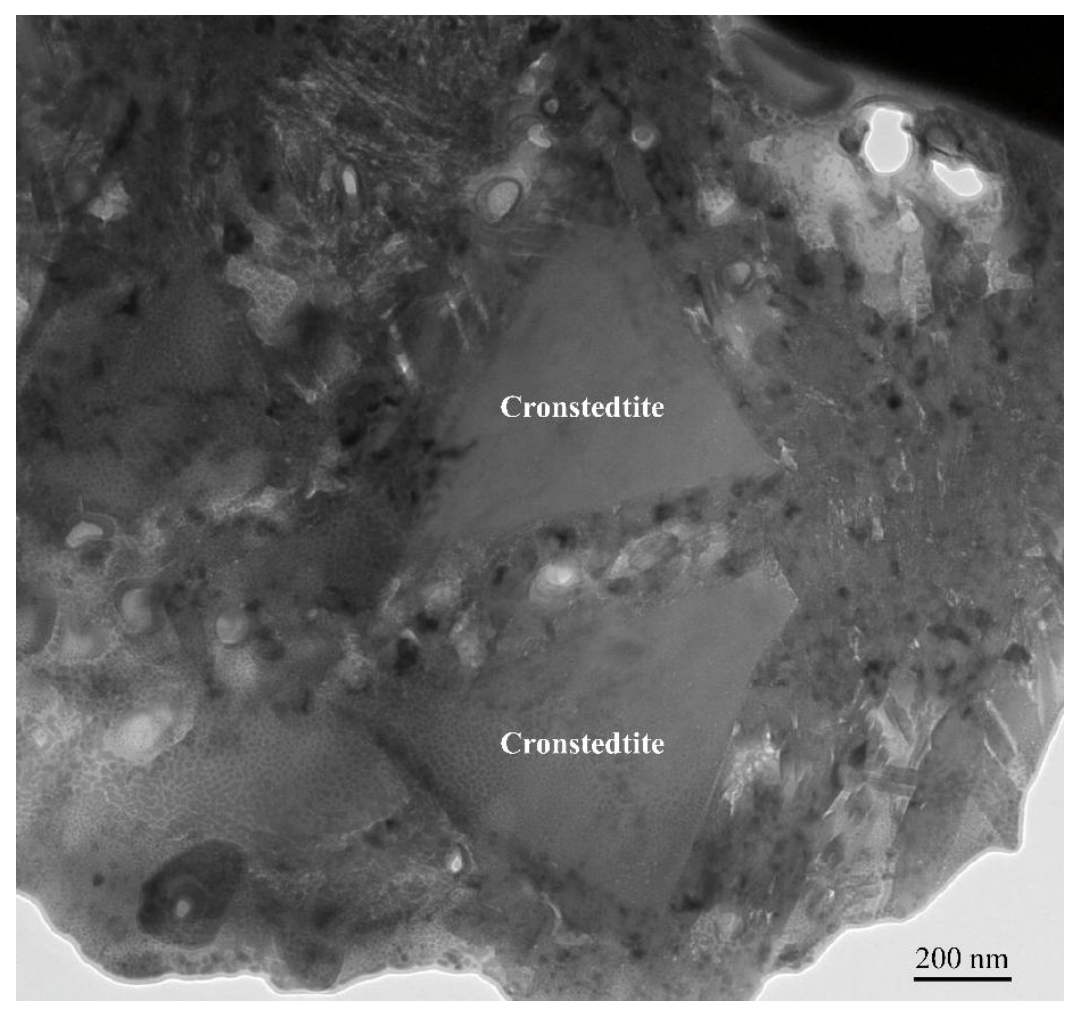

Figure 1. TEM image of some euhedral cronstedtite crystals found in the Paris meteorite. 

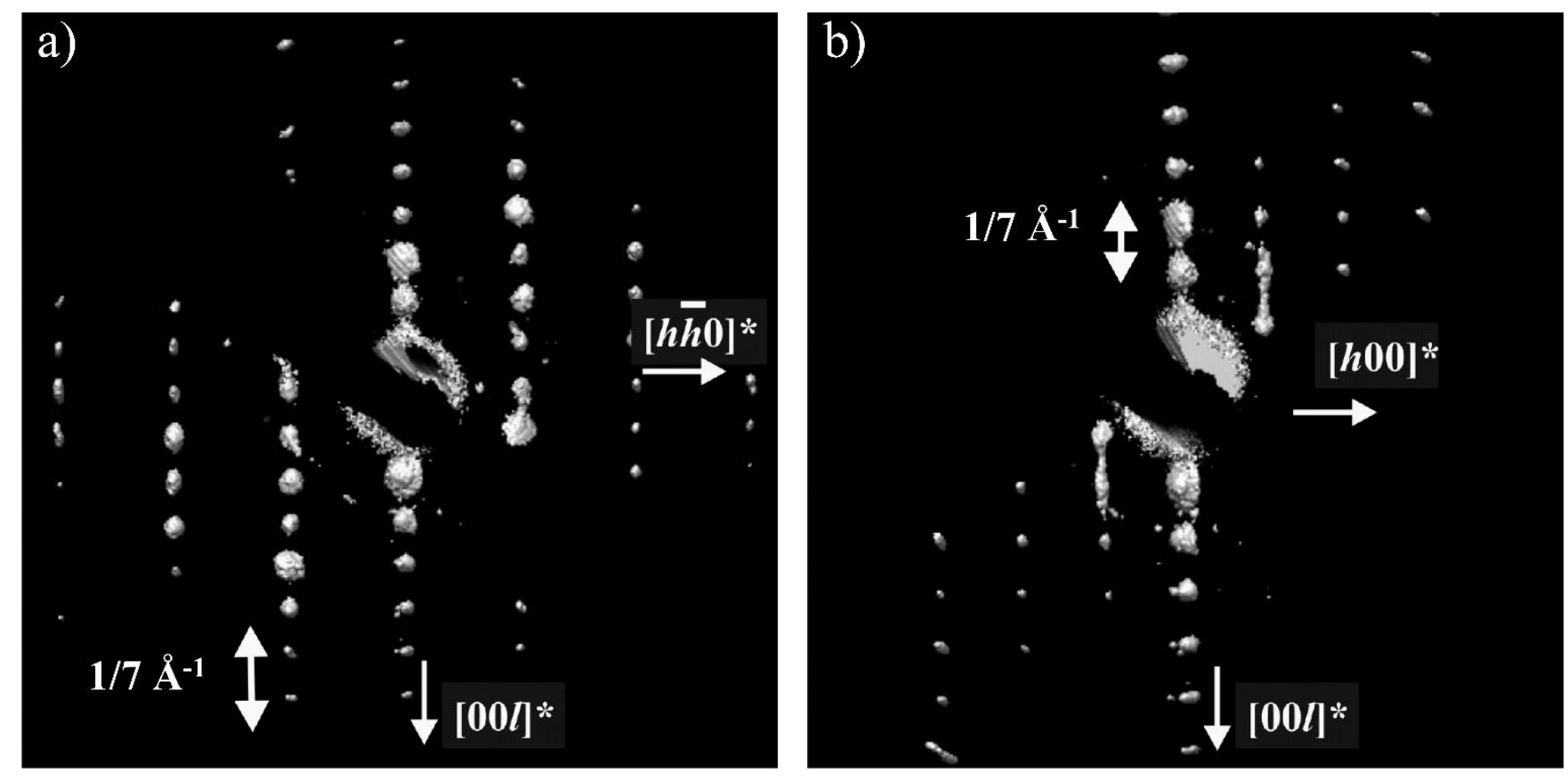

Figure 2. Sections of the 3D reconstructed diffraction volume of a sub-micrometric crystal of ordered $1 T$ cronstedtite. (a) Section corresponding to $\left(h h l_{\text {hex }}\right)^{*}$ plane and (b) section corresponing to $\left(0 k l_{\text {hex }}\right)^{*}$ plane. This figure was prepared using UCSF Chimera software. 


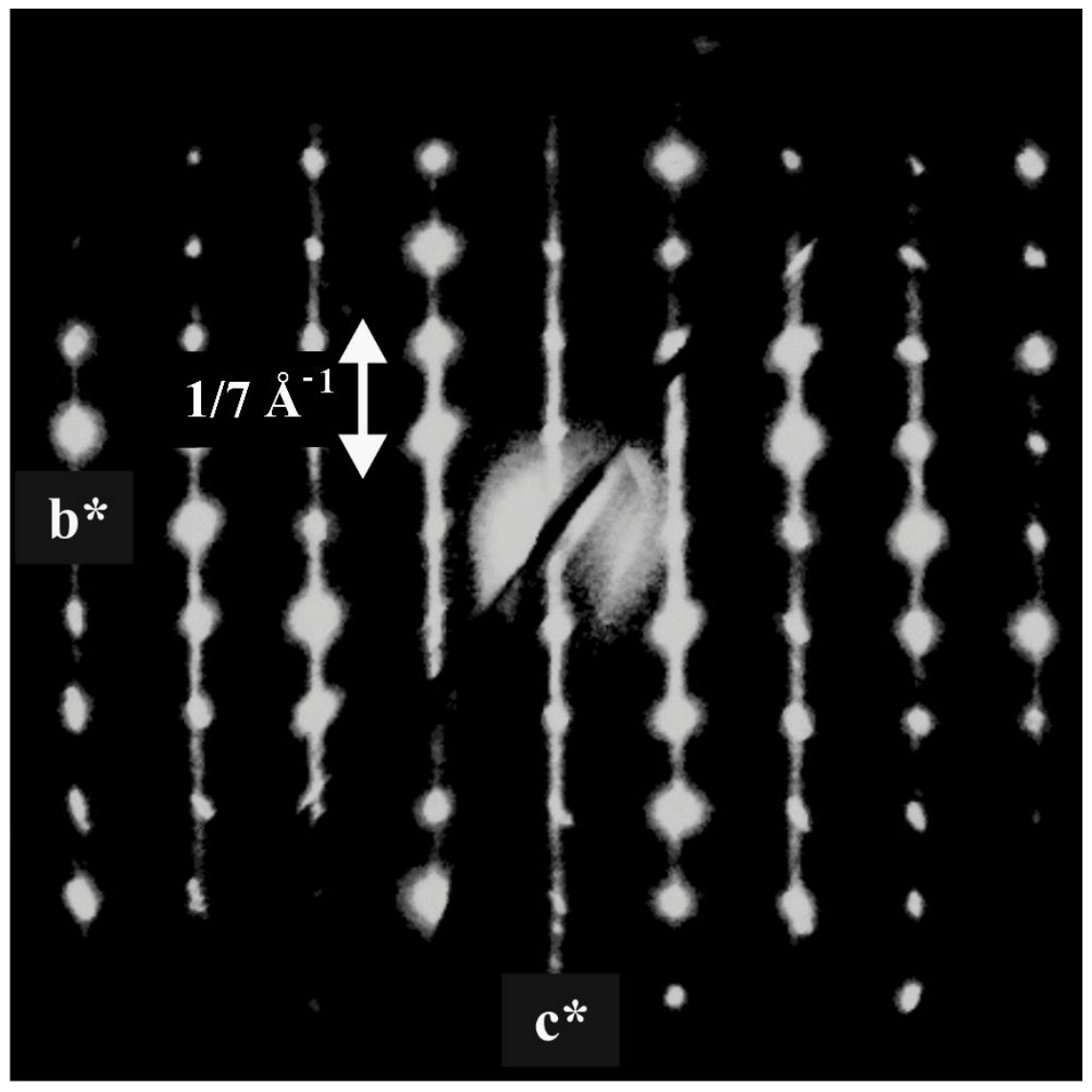

Figure 3. Projection of the 3D reconstructed diffraction volume of a sub-micrometric crystal of disordered crostedtite. Section corresponding to $\left(0 k l_{\text {hex }}\right)^{*}$ plane. 

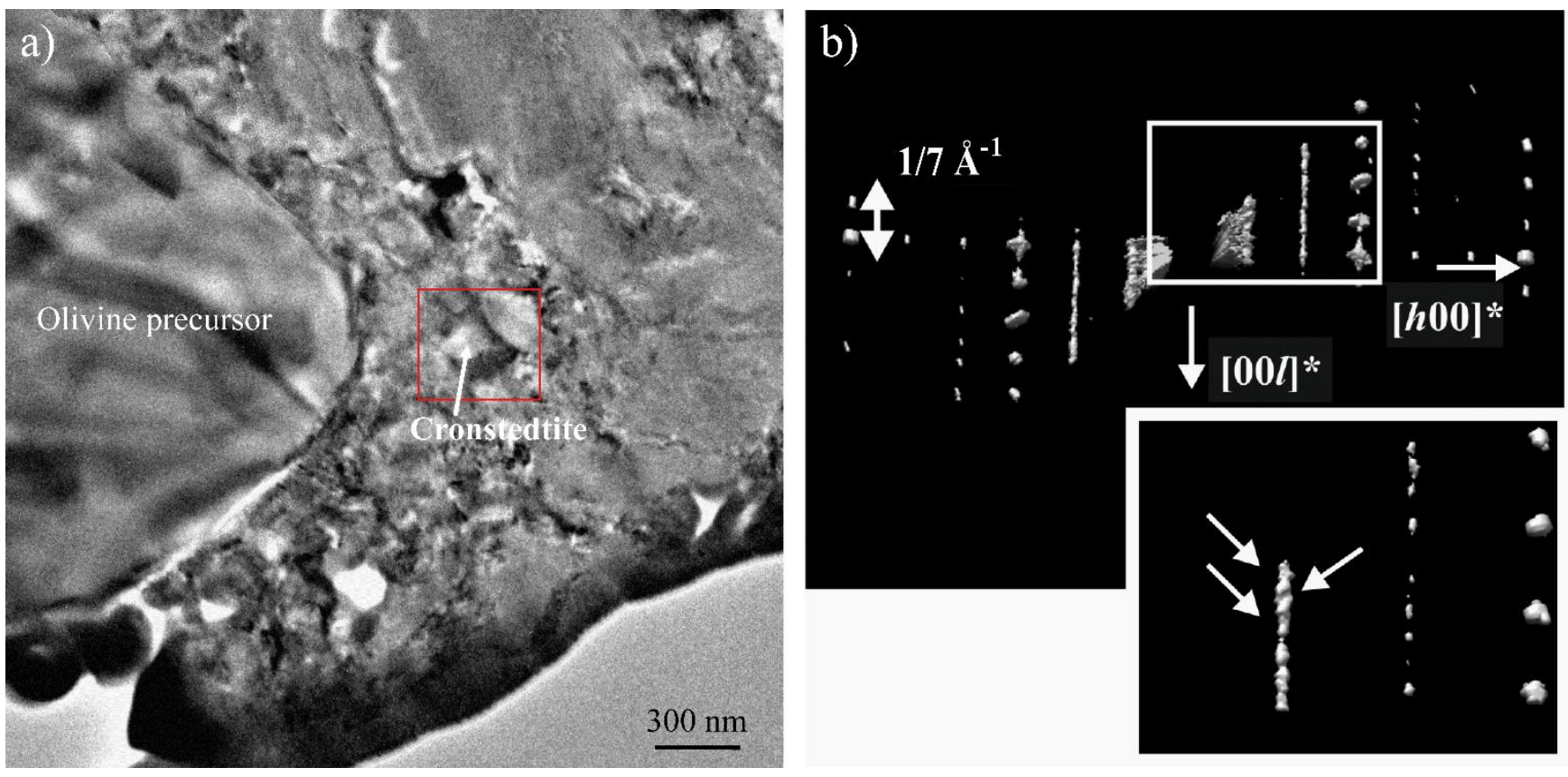

Figure 4. (a) TEM image of a cronstedtite crystal formed close to the remnant of a pseudomorphised olivine. (b) Section of the 3D reconstructed diffraction volume of a sub-micrometric crystal of partially disordered $3 T$ crostedtite. This section corresponding to $\left(h 0 l_{\mathrm{hex}}\right)^{*}$ plane and is obtained using UCSF Chimera software. In the down-right part of the panel is shown a higher-threshold zoom of the area marked by the white square. Reflections and intensity maxima corresponding to a periodicity of about $21 \AA$ are indicated along the $[10 l]^{*}$ row. 